\title{
Direct Chemical Proof of Different Glycosylation Patterns for Yeast Exo- and Endo-1,3- $\beta$-D-glucanases
}

\author{
By TOMAS G. VILLA, VICENTE NOTARIO* \\ AND JULIO R. VILLANUEVA \\ Department of Microbiology, Faculty of Sciences and Institute of \\ Biochemical Microbiology, C.S.I.C., University of Salamanca, Salamanca, Spain
}

(Received 6 June 1978)

\section{INTRODUCTION}

Notario et al. (1976b) purified and characterized an exo- $\beta$-D-glucanase (EC 3.2.1 .58) from cell-free extracts of Candida utilis and found that, although D-mannose and another compound of unknown nature were present, the enzyme was an acidic glycoprotein containing D-glucose as the main sugar in its carbohydrate moiety. Similar results were reported for an exo- $\beta$-D-glucanase purified from culture fluids of the same species (Villa et al., 1976). Lachance et al. (1977) have described an exo- $\beta$-D-glucanase purified from culture broth of the yeast Kluyveromyces aestuarii and that also appeared to be a glycoprotein.

In contrast the glycoprotein nature of the yeast endo-1,3- $\beta$-D-glucanases is a subject of controversy. Thus, Fleet \& Phaff (1974) reported an endo- $\beta$-D-glucanase (EC 3.2.1.6) purified from Schizosaccharomyces versatilis that completely lacked phosphorus and carbohydrate; whereas Biely et al. (1976) not only showed clearly that an endo- $\beta$-D-glucanase partially purified from Saccharomyces cerevisiae was effectively precipitated by concanavalin A, a property of typical yeast glycoproteins (i.e. mannan, invertase), but also suggested that endo- and exo- $\beta$-D-glucanases are distinctly glycosylated. This suggestion was based only on (i) the different interaction between exo- or endo-glucanases with concanavalin A and (ii) the general polysaccharide-binding properties of the lectin, and these authors recognized that direct proof of a difference in glycosylation patterns of exo- and endo- $\beta$-D-glucanases would require chemical analysis of the carbohydrate moieties from enzymic forms purified to homogeneity. This paper, which represents the completion of a previous study (Villa et al., 1975), provides such direct evidence for the different glycosylation of both kinds of enzyme.

\section{METHODS}

Pichia polymorpha, obtained from the Spanish Type Culture Collection, was used as the source of enzymes. Culture conditions, and methods of protoplast formation and enzyme preparation were similar to those used previously (Villa et al., 1975). The purification procedure was also similar but two new steps were added, at the beginning and the end of the process, to achieve further purification. Ammonium sulphate was added at $0{ }^{\circ} \mathrm{C}$ to crude enzyme extracts prepared from protoplasts and from culture fluids of whole cells. Material precipitated at 0 to 20, 20 to 40,40 to 60 and 60 to $80 \%$ saturation was collected by centrifugation, dialysed against $50 \mathrm{~mm}$-sodium acetate buffer, concentrated with polyethyleneglycol in the dialysis bags and then further purified according to the procedures of Villa et al. (1975). At the end, exclusion chromatography through a Sephadex G-50 column $(2 \times 40 \mathrm{~cm})$ was performed under the conditions described by Villa et al. (1975).

Filtration through concanavalin A-Sepharose 4B, isoelectric focusing experiments and gas-liquid chromatography were carried out as described by Notario et al. $(1976 \mathrm{~b})$. Polyacrylamide gel electrophoresis

* Present address: Department of Biochemistry, University of Cambridge, Cambridge CB2 1QW. 
was performed according to Weber \& Osborn (1969). Descending paper chromatography was done as indicated by Notario et al. (1976a) and the spots were developed by the method of Trevelyan et al. (1950).

Enzyme activity was tested against $0.25 \%(\mathrm{w} / \mathrm{v})$ laminarin in $50 \mathrm{~mm}$-sodium acetate buffer, $\mathrm{pH} 5 \cdot 5$, and expressed in arbitrary units as nmol glucose or equivalent reducing power released from the substrate per min, at $37^{\circ} \mathrm{C}$, per $\mathrm{mg}$ protein. Periodate-oxidized laminarin (Goldstein et al., 1965a) was used as a specific substrate for endo- $\beta$-D-glucanases.

Reducing sugars were determined by the method of Somogyi (1952) as modified by Nelson (1957). Free glucose was determined enzymically by the modification of Bruss \& Black (1978) of Keston's method (1956). Total carbohydrate was determined according to Dubois et al. (1956), and protein content was measured by the method of Lowry et al. (1951) or by its absorbance at $280 \mathrm{~nm}$ (or $254 \mathrm{~nm}$ when an ultraviolet monitoring system was used).

Laminarin was purchased from Koch-Light, and peroxidase (EC 1.11.1.7) and glucose oxidase (EC 1.1.3.4) were from Sigma. Gels for column chromatography were from Pharmacia, and all other reagents and common chemicals were of the best grade commercially available.

\section{RESULTS AND DISCUSSION}

Unless otherwise stated, the results reported here were the same for $\beta$-glucanase forms purified from supernatant fluids of whole cells and for those secreted by protoplasts. $\beta$-Glucanases I (endo-1,3- $\beta$-D-glucanase), II (exo-1,3-1,6- $\beta$-D-glucanase) and III (exo-1,3- $\beta$ D-glucanase) behaved as previously reported (Villa et al., 1976) throughout purification. After the last step all the fractions eluted from the Sephadex G-50 column were tested for total carbohydrate, protein and 1,3- $\beta$-D-glucanase activity. In all cases only one peak could be detected at $K_{\mathrm{d}}$ values of $0.08,0.16$ and 0.24 respectively for each enzymic form. The active fractions were then pooled and concentrated with polyethyleneglycol to a final volume of $5 \mathrm{ml}$. Specific activities were 930,2130 and 1760 units, respectively, for $\beta$-glucanases I, II and III from supernatant fluids of whole cells. Only minor differences were found in the relative amounts of each form secreted by protoplasts; in this case the specific activities were, respectively, 203, 468 and 450 units.

Samples of each purified form were used in polyacrylamide gel electrophoresis and isoelectric focusing experiments. The protein content of the samples was $150 \mu \mathrm{g}$ per gel in the electrophoresis experiments and $0.5 \mathrm{mg}$ in isoelectric focusing tests. In all experiments the purified enzymes appeared homogeneous, running as single well-defined bands which were always found at the same distance from the origin of the gels or at the same $\mathrm{pH}$ values at which maximum protein and carbohydrate values were detected. All of them behaved as electronegatively charged proteins moving close to the front marker in electrophoresis and showing isoelectric points (pI) at pH values of 3.9, 3.7 and 3.5, respectively. These results are in agreement with those reported by Arnold (1972) and Notario et al. (1976a) who showed this electronegativity as a peculiar property of $\beta$-glucanase enzymes.

These findings indicated that all the purified forms, including the endo-cleaving form (I), behaved exactly like other exo- $\beta$-D-glucanases whose glycoprotein nature has been reported previously (Notario et al., 1976b; Villa et al., 1976). Experiments were therefore performed to establish the nature of their sugar components. Samples of each form were hydrolysed for $6 \mathrm{~h}$ in $3 \mathrm{M}-\mathrm{HCl}$ at $105^{\circ} \mathrm{C}$ and the neutral sugar fractions were prepared as described by Villa et al. (1976). The presence of only D-glucose and D-mannose in all the hydrolysates was demonstrated by descending paper and gas-liquid chromatography. However, the relative proportions of these sugars were different for each enzymic form. Thus, D-mannose was predominant in $\beta$-glucanase I, whereas D-glucose was the main sugar in $\beta$-glucanases II and III. The ratio glucose/mannose for $\beta$-glucanase I was estimated to be $0.58 \pm 0.1$ (from colorimetric determinations and gas-liquid chromatography), whereas those for $\beta$-glucanases II and III were similar to that described for exo- $\beta$-D-glucanases from $C$. utilis (Notario et al., $1976 b$ ).

Contrary to the report of Fleet \& Phaff (1974), our results indicate that the endo- $\beta$ glucanases like the exo- $\beta$-glucanases are glycoproteins. This is the first direct chemical proof 
of the difference between yeast exo- and endo- $\beta$-D-glucanases with respect to their glycosidic constituents. The fact that these differences have been established for $\beta$-glucanases secreted by both protoplasts and whole cells appears to support our hypothesis that glycosylation takes place before or during secretion of these enzymes into the periplasmic space and no further glycosylation occurs during their secretion into the supernatant culture; this hypothesis was based on results indicating similar properties for 1,3- $\beta$-D-glucanases from yeast cell-free extracts or culture fluids (Notario et al., 1976a, b; Villa et al., 1975, 1976).

The interaction of the purified $\beta$-glucanases with concanavalin A was studied to obtain more information on the structure of their carbohydrate moieties. Consistent with their content of D-mannose, $\beta$-glucanases I were strongly bound to the lectin whereas the other forms failed to bind. Biely et al. (1976) suggested that the different precipitation of exo- and endo- $\beta$-D-glucanases by concanavalin $\mathrm{A}$ was due to the respective gluco- or manno-protein nature of these enzymes. Even though our results partially agree with this suggestion, the fact that both $\mathrm{D}$-glucose and $\mathrm{D}$-mannose were present in endo- and exo- $\beta$-D-glucanases supports the idea that the distinct interaction with concanavalin A must be explained in terms of structural differences between the enzyme molecules rather than in terms of the components of their carbohydrate moieties.

Despite their D-mannose content, the fact that both purified exo- $\beta$-D-glucanases (II and III) failed to bind to concanavalin A might be due to the lack of some structural requirement in the carbohydrate moiety (Agrawal \& Goldstein, 1965; Goldstein et al., 1965b; So \& Goldstein, 1968) or to the spatial disposition of the carbohydrate and polypeptide chains which, in turn, would make the concanavalin binding active sites more or less accessible to the non-reducing $\alpha$-pyranosyl ends of the polysaccharide portion. Amino acid analysis of the purified enzymic forms (in a Jeol-JCL-5AH autoanalyser) did not show any significant difference between them.

Further investigations are needed to establish the exact structural differences between endo- and exo-glucanases, because these differences may well be related to aspects such as the specific function of each type of enzyme in morphogenetic events, or the control mechanism which provides self-protection to the wall glucans against lysis by their own $\beta$-glucanases at certain stages of the cell cycle.

\section{REFERENCES}

Agrawal, B. B. L. \& Goldstein, I. J. (1965). Specific binding of concanavalin A to cross-linked dextran gels. Biochemical Journal 96, $23 \mathrm{C}$.

ArNold, W. N. (1972). The structure of yeast cell wall. Solubilization of a marker enzyme, $\beta$-fructofuranosidase, by the autolytic enzyme system. Journal of Biological Chemistry 247, 1161-1169.

Biely, P., Kratky, Z. \& Bauer, S. (1976). Interaction of concanavalin $A$ with external mannanproteins of Saccharomyces cerevisiae. Glycoprotein nature of $\beta$-glucanases. European Journal of Biochemistry 70, 75-81.

BruSs, M. L. \& BlaCK, A. L. (1978). Enzymatic microdetermination of glycogen. Analytical Biochemistry 84, 309-312.

Dubois, M., Gilles, K. A., Hamilton, J. K., Rebers, P. A. \& Smith, F. (1956). Colorimetric method for determination of sugars and related substances. Analytical Chemistry 28, 350-356.

Fleet, G. H. \& PhafF, H. J. (1974). Glucanases in Schizosaccharomyces. Isolation and properties of the cell wall associated $\beta$-1,3-glucanase. Journal of Biological Chemistry 249, 1717-1728.
Goldstein, I. J., HAY, G. W., Lewis, B. A. \& SMITH, F. (1965a). Controlled degradation of polysaccharides by periodate oxidation, reduction and hydrolysis. Methods in Carbohydrate Chemistry 5, 361-369.

Goldstein, I. J., Hollerman, C. E. \& Smith, E. E. $(1965 b)$. Protein-carbohydrate interaction. II. Inhibition studies on the interaction of concanavalin A with polysaccharides. Biochemistry 4, 876-883.

KeSTON, A. S. (1956). Specific colorimetric enzymatic reagents for glucose. Abstracts of Papers, 129 th Meeting of the American Chemical Society, $31 \mathrm{c}$.

Lachance, M. A., Villa, T. G. \& Phaff, H. J. (1977). Purification and partial characterization of an exo- $\beta$-glucanase from the yeast Kluyveromyces aestuarii. Canadian Journal of Biochemistry 55, 1001-1006.

Lowry, O. H., Rosebrough, N. J., Farr, A. L. \& RANDALL, R. J. (1951). Protein measurement with the Folin phenol reagent. Journal of Biological Chemistry 193, 265-275. 
Nelson, N. J. (1957). Colorimetric analysis of sugars. Methods in Enzymology 3, 85-86.

Notario, V., Villa, T. G., Benitez, T. \& Villaneuva, J. R. $(1976 a)$. $\beta$-Glucanases in the yeast Cryptococcus albidus var. aerius. Production and separation of $\beta$-glucanases in asynchronous cultures. Canadian Journal of Microbiology 22, 261-268.

Notario, V., Villa, T. G. \& Villanueva, J. R. $(1976 b)$. Purification of an exo- $\beta$-D-glucanase from cell-free extracts of Candida utilis. Biochemical Journal 159, 555-562.

So, L. L. \& Goldstein, I. J. (1968). Protein-carbohydrate interaction. XIII. The interaction of concanavalin $A$ with $\alpha$-mannans from a variety of microorganisms. Journal of Biological Chemistry 243, 2003-2007.
SOMOGYI, M. (1952). Notes on sugar determination Journal of Biological Chemistry 195, 19-23.

Trevelyan, W. E., Procter, D. P. \& Harrison, J. S. (1950). Detection of sugars on paper chromatograms. Nature, London 166, 444-445.

Villa, T. G., Notario, V. \& Villaneueva, J. R. (1975). $\beta$-Glucanases of the yeast Pichia polymorpha. Archives of Microbiology 104, 201-206.

Villa, T. G., Notario, V., Benitez, T. \& VillanueVa, J. R. (1976). Purification of an exo-1,3- $\beta$-glucanase from Candida utilis. Canadian Journal of Biochemistry 54, 927-934.

WeBer, K. \& OSBORN, M. (1969). The reliability of molecular weight determination by dodecyl sulfate-polyacrylamide gel electrophoresis. Journa of Biological Chemistry 244, 4406-4412. 